\title{
EXTRACORPOREAL LDL-CHOLESTEROL ELIMINATION IN THE TREATMENT OF SEVERE FAMILIAL HYPERCHOLESTEROLEMIA
}

\author{
Milan Bláha \\ University Hospital in Hradec Králové: I $^{\text {nd }}$ Department of Internal Medicine
}

\begin{abstract}
Summary: The extracorporeal elimination of LDL-cholesterol could be performed using the classic non-selective centrifuge or membrane plasmapheresis. The modern methods are more selective and effective. The atherogenic particules are removed from plasma by active colon or capsula. The methods include: cascade filtration, imunoadsorbtion, heparin-induced precipitation of LDL, thermofiltration, dextran-induced precipitation of LDL and direct adsorption of lipids (DALI). The regular LDL-apheresis is the life-saving technique in the treatment of homozygous familial hypercholesterolaemia. It is used in heterozygous familial hypercholesterolaemia when the patients do not respond to diet and drugs therapy, too. The regular LDL-apheresis treatment may be followed by the decreased frequency of angina pain episodes, the reduction of ECG changes during the bicycle ergometry and significant disappearance of tendinous xantomas. Some prospective randomised studies has shown even in this group of patients, resistant to conventional treatment, a significant regression of atherosclerotic changes.
\end{abstract}

Key words: LDL-cholesterol; Extracorporeal elimination; LDL-apheresis; Familial hypercholesterolemia

\section{Introduction}

Familial hypercholesterolemia and familial combined hyperlipidemia are genetic disorders which are, in their genotype, typical with high incidence of severe cardiovascular complications in young people. When the dietary measures together with combined medicamentous therapy are without any results it is necessary to approach to extracorporeal lipoprotein elimination.

The method of extracorporeal elimination of pathologically accumulated LDL- cholesterol were defined as $L D L$ apheresis.

Importance of LDL-apheresis in familial hypercholesterolaemia could be summarised as follows:

a) Technique is of unambiguous importance in treatment of homozygous patients - it is practically a case of lifesaving method. More than twenty years of experience with this method confirmed its unambiguous successfulness. Homozygous familial hypercholesterolaemia occurs in a frequency $1: 1,000.000$ of inhabitants. The cholesterol values rise to $1000 \mathrm{mg} / \mathrm{dl}$ (above 20-25 $\mathrm{mmol} / \mathrm{l})$. The patients die at an age of 23-25 years due to the complications of premature atherosclerosis. These homozygous patients, representing the highest risk group, allow already to conclude, that regression, primary prevention and secondary prevention can be achieved influencing both the quality of life and prolongation of survival (25). After Bruckert (11) there are three major reasons to treat homozygous patients: 1) their cardiovascular prognosis is very bad 2) drugs are ineffective and surgical procedures such as partial ileal bypass, portocaval shunt and liver transplantation have been associated with considerable morbidity, and 3) LDL apheresis decreases LDL-cholesterol and has been shown to be associated with improved life expectancy (4).

b) It is more difficult to form an opinion on the treatment efficacy in heterozygous patients, as these patients are generally recruited in a more advanced stage of their disease, are older and demonstrate a longer natural survival than homozygous patients. Though regression appears to be possible in young patients, the majority of them experience secondary prevention only, e.g. inhibition of the progress of (coronary) atherosclerosis, accompanied with an increase of the quality of their life. Heterozygous disorders occur in a frequency $1: 500$. The prevailing majority of these patients can be treated with a diet and hypolipidemic drugs only, $5-10 \%$ of these patients have to be treated with LDL-apheresis. It can be concluded in accordance with other authors, that LDL-apheresis seems to be a very useful method in these cases (25).

\section{Methods of extracorporeal elimination of cholesterol}

A number of methods for the extracorporeal elimination of cholesterol from intravasal volume can be used 
$(3,21)$. These techniques are summarised and shortly characterised in the Tab. 1 . We can divide them according to the ways of cholesterol elimination:

- non-specific

- specific

- selective.

Non-specific method means that virtually all other plasma proteins are eliminated together with the substrate to be removed. A selective technique eliminates unrelated plasma substituents together with the pathogenetic substrate, whereas a specific elimination removes the pathogenetic material exclusively. The degree of specificity is often related to the technology applied $(3,10)$.

Plasmapheresis is an example of non-specific and nonselective method. This is an older and well known method of extracorporeal elimination used in haematology (19). The principle consists in removing virtually all plasma proteins together with the LDL cholesterol. It was introduced by De Gennes in Paris in 1967 (12) and later elaborated by Thompson in London in 1977 (15). Blood is taken from one of the peripheral veins, plasma is separated either by centrifugation or by filtration and then removed. It is replaced by substituting fluids, which are crystalloid, colloids and donor's plasma. It was the base of cognition and starting point for application further methods $(13,14)$. The frequent use of plasmapheresis is not desirable (as it is necessary in homozygous patients) with regard to possible side-effects (17).

Cascade filtration: It was described by Agashi et al. (1). Plasma is separated by filtration from other blood compo- nents and then perfused through an additional filter. The size of its pores is adapted to separate LDL-cholesterol. This method is suitable especially at the beginning of the therapy because of improvement of the rheological conditions by retaining of fibrinogen, and this way patient's pains caused by angina could be reduced.

HELP - heparin induced extracorporeal LDL- precipitation: This technique was developed by Wieland, Seidel et al. (24). Plasma separated by filtration is exposed to acetate buffer. The insoluble complex of heparin-LDL develops in the presence of heparin at $\mathrm{pH}$ 5.12. The excessive heparin is picked up by an adsorber. The complex precipitates in an acid medium and is caught on a polycarbonate filter. Physiological plasma $\mathrm{pH}$ is restored by addition of bicarbonate and after volume adjustment, plasma is returned to the patient.

Thermofiltration: This technique was described by Nose (18). Plasma is removed by routine separation, heated to $40{ }^{\circ} \mathrm{C}$ and then filtrated through the second membrane. VLDL and LDL cholesterol is separated under thermal conditions, but HDL cholesterol is left. Plasma is returned to the patient after cooling.

Dextran induced LDL-precipitation: This technique was described by Antwiller (2) and Mabuchi et al. (15). In this method the low-molecular dextransulfate linked to micropalets of cellulose is used. The plasmatic lipoproteins containing apoprotein B (LDL, VLDL and triglycerides) are selectively absorbed.

LDL- apheresis:

It is based on immunoadsorption: plasma is pumped through a sepharose gel with coupled sheep antibodies

Tab. 1: The methods of extracorporeal cholesterol elimination (Adapted by Borberg, 1990, 1997).

\begin{tabular}{|l|l|l|}
\hline Author & Method & $\begin{array}{l}\text { Advantages/Disadvantages } \\
+/-\end{array}$ \\
\hline DE GENNES et al. (12) & Plasmapheresis & $\begin{array}{l}\text { + Rapid elimination } \\
\text { - Risk of infection and bleeding } \\
\text { - Danger of sensibilisation against administered proteins } \\
\text { during a long therapy }\end{array}$ \\
\hline AGASHI et al. (1) & Cascade filtration & $\begin{array}{l}\text { - Half selectivity, technical reasons, expensive, non accurate } \\
\text { separation, lower effectivity, single capsule }\end{array}$ \\
\hline STOFFEL et al. (22) & Immunoadsorbtion & $\begin{array}{l}\text { + Selectivity, high effectivity, specificity, no special side effects, } \\
\text { flexible, the possibility of regeneration of the used capsules } \\
\text { - Technically demanding, expensive }\end{array}$ \\
\hline Wieland et al. (12) & $\begin{array}{l}\text { HELP (heparin induced } \\
\text { LDL precipitation) }\end{array}$ & $\begin{array}{l}\text { - Half selectivity, no special side effects, effectivity } \\
\text { - Technically demanding, difficult, non-specific method, } \\
\text { a complicated principle }\end{array}$ \\
\hline ANTWILLER et al. (2) & $\begin{array}{l}\text { Dextransulphate induced } \\
\text { LDL precipitation }\end{array}$ & $\begin{array}{l}\text { + Selectivity, effectivity } \\
\text { - Unclear activity of macromolecules at a higher temperature }\end{array}$ \\
\hline MABUCHI et al. (15) & LDL-adsorptivity, high effectivity, no special side effects \\
\hline Co. FRESENIUS (9) & $\begin{array}{l}\text { DALI (Direct Adsorption } \\
\text { of Lipids) }\end{array}$ & $\begin{array}{l}\text { + Selectivity, high effectivity, no special side effects, a possibility } \\
\text { of capsule's regeneration } \\
\text { - Technically demanding }\end{array}$ \\
\hline $\begin{array}{l}\text { + Selectivity, no special side effects } \\
\text { - Limited capacity, economically demanding }\end{array}$ \\
\hline
\end{tabular}


against human apoprotein B 100, which forms the main protein component of LDL-cholesterol.

LDL-apheresis also named immunoadsorption or therapeutic affinity chromatography is the specific extracorporeal on-line LDL-elimination therapy. The concept was suggested by Stoffel in 1981 (22) and introduced into the clinical practice by Borberg also in 1981 (6).

The LDL-apheresis system consists of primary plasma separation generally performed with blood cell separators working at whole blood flow rates from 50 to $80 \mathrm{ml} / \mathrm{min}$ and plasma flow rates of 30 to $50 \mathrm{ml} / \mathrm{min}$ and a differential plasma separation system consisting of a device automatically performing the repetitive, cyclic loading and desorption of 2 columns (see Fig. 1). The capacity of the system is theoretically infinitive due to 2 different principles. The biochemistry of the adsorber system led with increasing purification and improvement to a loading capacity of $8 \mathrm{~g} \mathrm{LDL}$ cholesterol per column and even more. Simultaneously the clinical approach is permitting to load and desorb each pair of columns as often as it is necessary for the treatment. The treatment time thus varies according to the pre-treatment cholesterol level of the patient. The essentials of the approach are summarised in Tab. 2 (after Borberg, 1997-6).

As mentioned above, primary plasma separation is generally performed with continuous flow blood cell separators - these devices are well known to the staff in transfusion medicine and have some advantages. The peripheral veno-venous access avoids all potential risks of a central venous or arterial access. As the disposables of blood cell separators are generally less demanding compared to plasma filters, the selection of the appropriate primary plasma separation device is also of economical interest. Last but not least modern blood cell separators are characterised by multipurpose application, are easy to handle - the advantage greatly appreciated by the staff in a blood-transfusion centre (4).

The adsorber columns consists of a sheep antibodies against apoprotein B coupled to sepharose 4B after bromcyanide activation. Beside the advantages of LDL-apheresis due to the specificity of elimination, the capacity of the system and the versatility of the technical device which may be used for all kinds of different adsorbers, the safety of the system was confirmed by many laboratory investigations and statistical data. The LDL-cholesterol can be decreased to the desired normal or subnormal level without a loss of normal plasma proteins or HDL cholesterol (see Graph 1). Long term treatments lead to a steady-state between synthesis rate and removal after 5 to 7 apheresis, if the treatments are performed weekly. The number of days under $200 \mathrm{mg} / \mathrm{dl}$ (under $5 \mathrm{mmol} / \mathrm{l}$ ) is supposed to be crucial for regression of atheromatosis $(4,6)$.

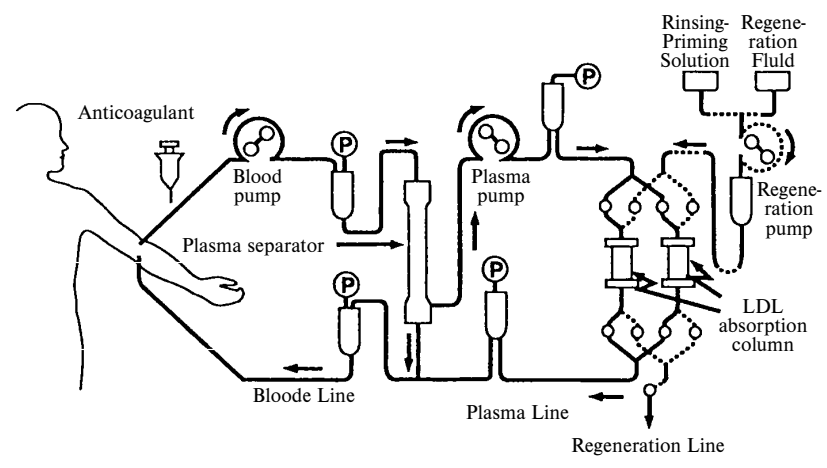

Fig. 1: The principle of LDL-adsorption.

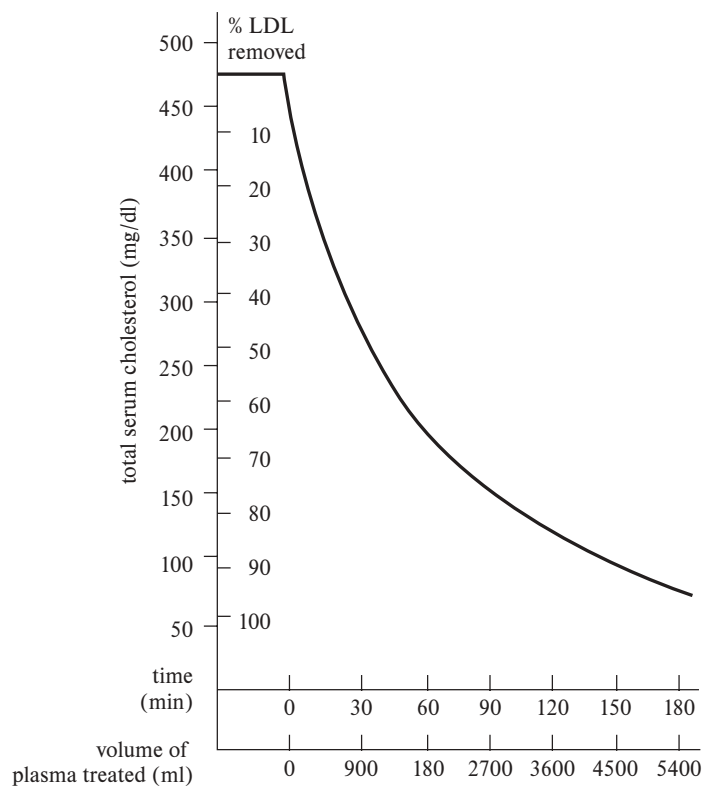

Graph 1: Decrease of cholesterol level during LDL-apherese (after Borberg, 1997).

Tab. 2: Essential of LDL-Apheresis.

\begin{tabular}{|l|l|l|}
\hline I. BIOCHEMICAL & II. TECHNICAL & III. ECONOMICAL \\
\hline $\begin{array}{l}\text { - Therapeutic on-line } \\
\text { affinity chromatography }\end{array}$ & - Repetive cycling of 2 columns & $\begin{array}{r}\text { REUSABILITY } \\
\text { (for 50-100 treatments) }\end{array}$ \\
$=$ SPECIFICITY of elimination & $=$ Virtual indefinite CAPACITY & \\
$=$ Reusability & - Versatility of the secondary separation & \\
& $=$ Applicable to all kinds of secondary separation & \\
\hline
\end{tabular}


DALI - Direct Adsorption of Lipids - the first LDL-adsorption that eliminates LDL cholesterol directly from whole blood, introduced into the clinic by Co. Fresenius, Germany, 1996. This apheresis system is applicable to continuous hemoperfusion of human whole blood. It seems to be very efficient and works without significant side-effects $(6,9)$.

\section{Indications to the therapy}

Determination of indication criteria for LDL-apheresis therapy is necessary for these reasons:

- the multidisciplinary approach,

- the social importance due to frequency of severe LDL hypercholesterolaemia in population,

- the relatively high costs connected with secondary atherosclerosis prevention.

The recently achieved degree of scientific knowledge concerning some risk factors for the rise and development of atherosclerosis shows that LDL-cholesterolaemia is the most important risk factor for premature development of atherosclerosis, LDL-cholesterol reduction became the main measure for the primary and secondary prevention of coronary heart disease. Some recommendations for the indication of long-term LDL-apheresis therapy were elaborated in several countries. We are using a modification of these indication criteria (5) - according to the order of importance:

1. Homozygous familial hypercholesterolaemia: a clear and unquestionable indication

2. Patients with hypercholesterolaemia who were unsuccessfully treated by a strict diet and pharmacological therapy, particularly in the following cases:

a) Coronary atherosclerosis which cannot be resolved cardioasurgically or by methods of invasive cardiology (PTCA, stent) because of disadvantageous anatomical situation or diffuse coronary changes.

b) Patients after cardiosurgical or invasive cardiological intervention in which high cholesterolaemia survives in spite of the maximal pharmacotherapy and there remains a high risk of the progression of atherosclerotic changes and restenosis in the incriminated region.

\section{Case report}

Typical course of the disease and the therapy are described further.

Female patient, born in 1979 , was followed at a Centre for nutrition and metabolic disorders, Teaching hospital, Charles University in Hradec Kralove for 12 years.

Serious hypercholesterolaemia and tendinous xanthomas in the area of Achilles tendon and on the back of the palms were found from 6 years of her age. The bicycle ergometry was performed with physiological result and any symptoms of ischaemic heart disease were not proved. Coronarography has not been performed yet. The pa- tient's parents are followed up at the same Centre because of heterozygous form of familial hypercholesterolaemia, their therapy is based on diet and statins, and we have not found any symptoms of heart ischaemic disease yet. The patient's grandmother died of the second myocardial infarct at the age of 68 years, she had her first heart attack at the age of 48 years and according to anamnestical data, she suffered from abdominal angina as well.

Our patient was treated by the sequestrants of bile acids in a dose of $12 \mathrm{~g}$ daily since 6 years of her age, she was on a strict diet, but without pronounced effect, though there was a very good compliance given by her family and patient's motivation. The average level of total cholesterol ranged from 15 to $22 \mathrm{mmol} / 1$.

The plasma exchange was the initial method used in the treatment at our department. The cholesterol level at the start is given in the Graph 2. The technique was carried out in weekly interval as far as possible, the cholesterol level decreased, but the effect was not satisfactory - see Graph 2, as the required cholesterol level was not reached. The treatment by LDL- apheresis in a weekly interval was consequently introduced in 1996. (The interval was only exceptionally longer either due to serious personal reasons of the patient or technical reasons.) From 1998, the treatment was carried out in two weeks interval. We washed regularly 71 of plasma. The cholesterol values after one procedure decreased usually under the level of $2 \mathrm{mmol} / 1$, the mean values were below the base limit, see - Graph 2 . It is generally considered as a decisive fact for the prognosis $(6,7)$ and the result was not possible to reach with other accessible methods of treatment. In the first days after the apheresis, the cholesterol level is significantly below the norm. We suppose, that the progress of the disease can be interrupted and resorption of the plaques will continue, because we observe the disappearing of the xanthoms on the hands, their reducing and softening above the Achilles tendon. The time of this treatment is too short to evaluate the therapy in details.

Our patient tolerates the treatment very well, without any detectable side-effects.

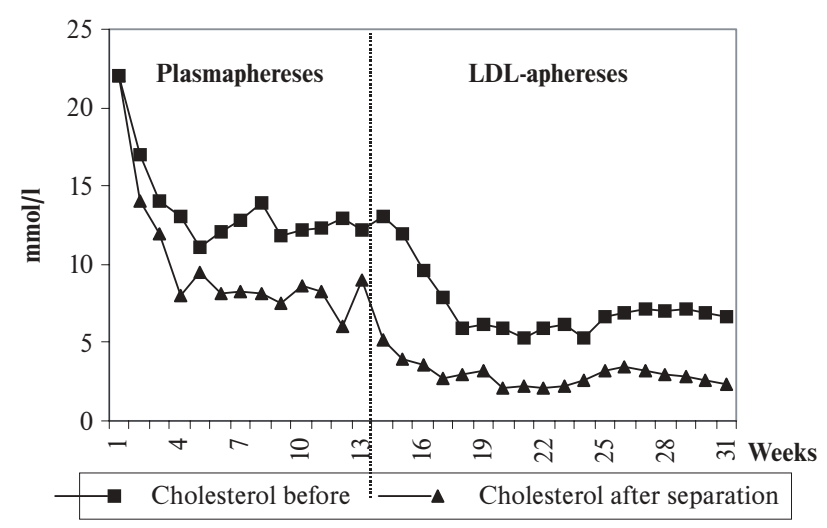

Graph 2: The course of treatment - our female patient. 


\section{Conclusion}

Extracorporeal LDL-cholesterol elimination is the method of choice in a limited group of patients with an extremely high risk of premature or accented coronary atherosclerosis due to a high LDL-cholesterol level. A decision as to whether a particular patient will be treated by some of the method of extracorporeal LDL-cholesterol elimination should be made on the basis of a careful and detailed clinical and laboratory examination of the patient. Our own experience and literary data demonstrate the longterm safety, efficiency and ability of the LDL-apheresis to retard and in most cases to stop or even to cause regression of the coronary atherosclerosis which cannot be resolved otherwise $(5,25)$.

This method is suitable for the primary and secondary prevention of atherosclerosis. LDL-apheresis provides good results from the medical and also from the economic point of view. The number of acute coronary emergencies in high-risk patients (particularly in young people) is reduced and the long-term results of demanding cardio surgical interventions in the coronary bed and the results of PTCA and stent therapy are improved.

\section{Acknowledgement}

This work was supported by the grant IGA MZ CR No 6549-3.

\section{References}

1. Agashi T, Kaneko J, Hasuo Y et al. Double filtration plasmapheresis with no or minimal amount of blood derivative for substitution. In: Sieberth HG, eds. Plasma exchange, Plasmapheresis - plasmaseparation. New York, Stuttgart: Schattauer, 1980: 53-7.

2. Antwiler GD, Dau PC, Lobdell DD Treatment of familial hypercholesterolemia by precipitation of low density lipoproteins with dextransulfate. Manuscript. After Borberg, H. LDL-Apheresis and LDL-Elimination Therapies. In: European School of Haematology, eds. $2^{\text {nd }}$ Seminar of Applied Technology in Haemapheresis (Proceedings), Paris: ESH 1997:1-8.

3. Bambauer R, Scheil R, Latza R. Current topics on low-density lipoprotein apheresis. Ther Apher 2001;5:93-300.

4. Bláha V, Zadák Z, Bláha M, Havel E, Vyroubal P, Malý J. Klinické využití imunoadsorpční LDL-aferézy $\mathrm{v}$ léčbě hypercholesterolémií. Diabetol Metabol Endokrinol Výživa 2001;4(Suppl. 4): 36.

5. Bláha $\mathrm{V}$, Zadák $\mathrm{Z}$, Bláha $\mathrm{M}$ et al. Selekční kritéria $\mathrm{k}$ léčbě závažných hyperlipoproteinémií metodou LDL-aferéz. Cas Lek ces 1998;137:424-9.

6. Borberg H LDL-Apheresis and LDL-Elimination Therapies. In: European School of Haematology, eds. $2^{\text {nd }}$ Seminar of Applied Technology in Haemapheresis (Proceedings), Paris: ESH 1997:1-8.

7. Borberg H. Results of an open, longitudinal multicenter LDL-apheresis trial. Transfusion Sci 2000;20:83-94.
8. Borberg H, Gaczkowski A, Hombach V, Oette K, Stoffel W. Treatment of familial hypercholesterolemia by means of specific immunoadsorbtion. J Clin Apheresis 1988;4:59-65.

9. Bosh T. Direct adsorption of lipoproteins from whole blood by DALI apheresis: technique and effects. Ther Apher 2001;5:239-43.

10. Braun N, Bosch, T. Immunoadsorption, current status and future developments. Expert Opinion Investig Drugs 2000;9:2017-38.

11. Bruckert E. Efficacy of LDL-apheresis and the less specific technique which is plasmapheresis. Transfusion Sci 1999;20:43-7.

12. De Gennes JL, Tourraine R, Maunand B, Truffert J, Laudat P. Forms homozygotes cutanéo-tendineuses de xanthomatose hypercholestérolémique dans une observation familiale exemplaire. Essai de plasmaphérèse à titre de traitment héroique. Bull Mem Soc Hop Paris 1967;118:1377-1402.

13. Drew M.J. Plasmapheresis in the dysproteinemias. Ther Apher 2002;6:45-52.

14. Jacob B. Plasmapheresis - principles and practice. J Indian Med Ass 2001;99:364-67.

15. Mabuchi H, Michishita J, Mitsuaki T et al. A new low density lipoprotein apheresis system using two dextran sulphate cellulose columns in an automated column regenerating unit (LDL continuous apheresis). Atherosclerosis 1987;68: $19-25$.

16. Nakaji S. Current topics pn immunoadsorption therapy. Ther Apher 1980;5: 301-5.

17. Norda R, Berséus O, Stegmayr B. Adverse events and problems in therapeutic hemapheresis. A report from the Swedish registry. Transfusion Apher Sci 2001;25: 33-41.

18. Nose Y, Usami M, Malchesky PS et al. Clinical thermofiltration: initial application. Artif Organs 1985;9:425-7.

19. Omokawa S. Current topics on centrifugal plasmapheresis technology. Ther Apher 2001;5:264-9.

20. Seidel D, Armtsrong VW, Schuff-Werner P. The HELP-LDL-Apheresis Multicentre Study, an angiographically assessed trial on the role of LDL-apheresis in the secondary prevention of coronary heart disease. I. Evaluation of safety and cholesterol-lowering affects during the first 12 month. Eur J Clin Investig 1991;21:375-83.

21. Schuff-Werner P, Holdt B. Selective hemapheresis, an effective new approach in the therapeutic management of disorders assotiated with rheumatological impairment: mode of action and possible clinical indications. Artif Org 2002;6: $117-23$

22. Stoffel WH, Borberg H, Greve V. Application of specific extracorporeal removal of low density lipoprotein in familial hypercholesterolemia. Lancet 1981;2: $1005-7$.

23. Thompson GR, Lowentahl R, Myant NB. Plasma exchange in the management of homozygous familial hypercholesterolaemia. Lancet 1975;2:1209-11.

24. Wieland H, Seidel D. A simple method for precipitation of low density lipoproteins. J Lipid Res 1983;24:904.

25. Yamamoto A, Harada-Shiba M, Kawaguchi A, Tsushima M. Apheresis technology for prevention and regression of atherosclerosis. Ther Apher 2001;5: 221-5.

Submitted May 2002.

Accepted February 2003.

Prof. MUDr. Milan Bláha, CSc., University Hospital in Hradec Králové, $I^{n d}$ Department of Internal Medicine, 50005 Hradec Králové, Czech Republic. e-mail: blaha@fnhk.cz 